\title{
Response preferences and choice-sequence preferences: II. Perceptual and motor conditions.'
}

\author{
IRMA R. GERJUOY, JOHN J. WIKTERS, JR., JOSE' M. ALVAREZ AND MARTHA M. PULLEN
}

EDWARD R. JOHNSTONE TRAINING AND RESEARCH CENTER, BORDENTOWN, N. J.

Adolescent educable retardates, equal MA normals, and equal CA normals were presented a binary-choice task in which they were required to respond to the side on which a central vertical line appeared to be located. A lateral preference was found when a verbal response was required, but not when a motor response was required. An inverse relationship was found between lateral preference and altemation behavior.

When two equal-sized geometric figures are exposed side by side with unlimited exposure, retardates and equal CA normals report the right-hand stimulus as the larger significantly more often than the left-hand stimulus (Winters \& Gerjuoy, 1965; Gerjuoy \& Winters, 1966). The same result was found with equal MA normals in an unpublished study. Under tachistoscopic exposure, on the other hand, equal CA normals, but not retardates, report this right-side enlargement (Gerjuoy \& Winters, 1966; Winters \& Gerjuoy, 1966). In these studies an inverse relationship has been found between a right-side preference and an alternation tendency.

Iwahara (1959) has pointed out the relationship between lateral preferences and alternation behavior for normal children and adults in a binary-choice task without feedback. He found that adults have stronger right-side preferences than children, but that children have stronger alternation tendencies than adults.

Two purposes of the present study were to determine whether apparent lateral displacements of a central vertical line can occur with a relatively long exposure time ( 3 sec.), and whether there is a relationship between such displacements and choice-sequence preferences.

Since the responses of retardates were to be compared with those of normals, an additional purpose of this study was to compare the discrimination ability of normals and retardates when the vertical line was actually off-center and to see if there were tendencies in any of the three populations: adolescent educable retardates, equal MA normals, or equal CA normals, to make more errors to one side than the other.

A final question that this study was designed to test was whether a lateral preference was a function of the mode of response. To test this hypothesis half the Ss presented with the centrally-located vertical line were required to give a verbal response, the remaining Ss were required to make a motor response.

\section{Method}

Subjects. The Ss were 90 adolescent educable retardates $(\overline{\mathrm{CA}}=15.8$ yr., $\sigma=1.1$ yr.; $\overline{\mathrm{IQ}}=64.22, \sigma=8.24), 90$ equal MA normals $(\overline{\mathrm{CA}}=10.1 \mathrm{yr} ., \sigma=.7 \mathrm{yr} . ; \overline{\mathrm{IQ}}=103.2$, $\sigma=14.2)$, and 90 equal CA normals $(\widehat{\mathrm{CA}}=15.4 \mathrm{yr} . ; \sigma=$ .84 yr.; $\overline{\mathrm{IQ}}=104.5, \sigma=11.8$ ). Each population was divided into four subgroups of varying sizes: one subgroup of 10 Ss was run in condition A, perceptual; one subgroup of $20 \mathrm{Ss}$ was run in condition $\mathrm{B}$, perceptual; and two subgroups of $30 \mathrm{Ss}$ each were run in condition $\mathrm{C}$, one perceptual (Cp), and one motor $(\mathrm{Cm})$.

Apparatus and stimulus materials. A modified Gerbrands tachistoscope was used to present the stimulus materials. S's eyes were $79 \mathrm{~cm}$ from the stimuli. The exposure field had a luminance of $2.38 \mathrm{ft}$. $-\mathrm{c}$. Two response keys were mounted in front of the Ss in the motor condition only.

The stimulus materials for the perceptual condition consisted of a horizontal black outline rectangle $7 \times 14$ $\mathrm{cm}$, plus a vertical line $4 \mathrm{~cm}$ long. A circle was placed outside the rectangle on one side; a square was placed symmetrically on the other side. The two geometric figures were equated for subjective size by a group of judges. In condition $A$ the line was $.5 \mathrm{~cm}$ to one side or the other of the center of the rectangle, in condition $B$ the line was $.25 \mathrm{~cm}$ to one side or the other of the center of the rectangle and in condition $\mathrm{Cp}$ the line was in the center of the rectangle. The stimuli were the same for the motor subgroup $(\mathrm{Cm})$ of condition $\mathrm{C}$ except that the geometric forms were obliterated.

Procedure. Prior to the experiment, Ss in the perceptual condition were trained in identification of the geometric forms and in the responses of the experimental task, indicating by the response "circle" or "square" which side the line was closer to. In the training cards the vertical line was displaced noticeably from the center. Four pretraining cards were used outside the tachistoscope and two additional cards were used for further pretraining with the tachistoscope. After $E$ was assured that $S$ understood the task, i.e., he could name the geometric form the line was closer to, he was given instructions for the experiment proper. The pretraining for the motor condition was similar, but $S$ was taught to press the key on the side the line was closer to.

Each S received 20 trials. The side of the geometric figures, and the side the line was closer to for conditions $A$ and B, were counterbalanced. Each card was exposed for 3 sec.; there was a $17 \mathrm{sec}$. intertrial interval. Results

Perceptual Condition. For no group was there a preference for one geometric form over the other.

In the $A$ condition, $.5 \mathrm{~cm}$ displacement, the errors were negligible for all three populations. The discrim- 
ination was as easy for retardates as for normals. In the $B$ condition, $.25 \mathrm{~cm}$ displacement, retardates made the most errors, 105, equal MA normals made fewer, 74, and equal CA normals made the fewest, 33. All groups differed significantly from one another. An analysis of the side of the error for each population revealed that there was no significant lateral bias for either of the older groups, but that the equal MA normals displaced the line from right to left significantly more often than from left to right $\left(X^{2}=26.2, p<.001\right)$.

In the $\mathrm{Cp}$ condition there was no lateral bias for any population on the first response. Overall, however, equal MA Ss differed significantly from the older groups in side preference $\left(X^{2}=12.86, p<.001\right)$. Equal MAs made more left responses whereas retardates and equal CAs made more right responses. Analysis of alternation behavior of the three populations under the Cp condition reveals that only retardates alternated their responses (circle and square) above chance $\left(X^{2}=8.50, p<.01\right)$. In terms of left and right position, however, no group alternated the side of their responses more than would be expected by chance; in fact, they all perseverated above chance.

Motor Condition. On the first trial of the $\mathrm{Cm}$ condition significantly more retardates and equal CAs made a right response than a left response $\left(X^{2}=4.80, p<.05\right)$. Equal MA normals had no significant side preference. Over all trials no group had a significant lateral preference, and only equal CAs had a significant choicesequence preference, perseveration $\left(X^{2}=5.08, p<.05\right)$. Because group preferences showed no consistency, an analysis was performed for each group to determine whether a relationship existed between lateral preferences and perseveration. The rank order correlations for the three populations were: retardates, $.51(p<.01)$, equal MA normals, $.74(p<.001)$, and equal CA normals, .71 $(p<.001)$. Ss who responded more to one side than the other perseverated their responses more than Ss who responded more equitably to both sides. Discussion

Since an overall lateral displacement of a centrallylocated vertical line occurred for all groups in the perceptual condition and none of the groups in the motor condition, "it is not clear whether the results reflected a true perceptual displacement or merely a preference to report more frequently on one side than the other. The perceptual condition was more complicated visually since there were two geometric forms in the visual field in addition to the vertical line and horizontal rectangle that enclosed it. There may have been some interaction between the line and figure but, if so, there was still no preference for either figure.

The perceptual and motor conditions also differed with respect to the first response. There was no.initial preference in the perceptual condition, but the older groups showed an initial right-side preference in the motor condition. An initial lateral preference which dissipates after the first trial has been found in a number of binarychoice motor tasks (Gerjuoy \& Winters, in press).
The inverse relationship between lateral preferences and alternation tendencies is reflected by the results from the perceptual condition. All groups had strong lateral preferences and above chance perseveration tendencies for left and right responses. It should be noted that, in terms of the responses "circle" and "square," it is the retardates (that group which has always alternated the most over a number of studies) who alternate these responses above chance. Since circle and square were assigned randomly to the left and right over trials, the experimental situation allowed for two different kinds of alternation or perseveration, that of the verbal responses and that of the two sides. In order to compare the two modes of response, perceptual and motor, only the left-right position alternation or position perseveration has been considered. Whether the behavior of Ss in the perceptual condition was primarily determined by the laterality of the choices or by the verbal responses is unknown.

Inspection of the frequency distributions of right responses for the three populations under the two response conditions reveals that the distributions are far from normal whether or not there is a lateral preference. Some Ss in each group gave predominantly left or predominantly right responses, but in the motor condition there was no overall lateral bias. Those Ss who have a strong lateral bias will, of course, tend to perseverate above chance. Ss without such a bias can still perseverate above chance (in the extreme they could give 10 left responses followed by 10 right responses), or they could alternate above chance (in the extreme every left response could be followed by a right response and vice versa). Rank order correlations were performed to determine whether, in the motor condition, those Ss with strong lateral biases perseverated more than those Ss without lateral biases. The correlations were significant for all three populations, indicating that the stronger the lateral bias the more perseveration or, conversely, the weaker the bias the more alternation.

\section{References}

Gerjuoy, I. R., \& Winters, J. J., Jr. Lateral preference for identical geometric forms. II. Retardates. Percept. \& Psychophys., 1966, $1,104-106$

Gerjuoy, I. R., \& Winters, J. J., Jr. Development of Iateral and choice-sequence preferences. In N. R. Ellis (Ed.), International review of research in mental retardation. Vol. III. New York: Academic Press. In press.

Iwahara, S. Studies in spontaneous alternation in human subjects: III. A developmental study. Jap. Psychol. Res., 1959, 1, 1-8.

Winters, J. J., Jr., \& Gerjuoy, I. R. Gamma movement: Field brightness, series, and side of the standard. Psychon. Sci., 1965, 2, 273-274.

Winters, J. J., Jr., \& Gerjuoy, I. R. Lateral preference for identical geometric forms: I. Normals. Percept. \& Psychophys., 1966, 1, 101-103.

\section{Note}

1. The authors wish to express appreciation to Dr. John F. Almond, Principal, Trenton Public Schools, Mr. Samuel Kaltovich and Mrs. Ethel K. Elliott, Principals, Florence Township Schools for their generosity in providing the normal students. We also wish to thank Herman H. Spitz for a critical reading of the manuscript. 